\title{
Isotope dilution challenge
}

\author{
Enea Pagliano
}

(C) Her Majesty the Queen in Right of Canada 2014

We would like to invite you to participate in the Analytical Challenge, a series of puzzles to entertain and challenge our readers. This special feature of "Analytical and Bioanalytical Chemistry" has established itself as a truly unique quiz series, with a new scientific puzzle published every other month. Readers can access the complete collection of published problems with their solutions on the ABC homepage at http://www.springer.com/abc. Test your knowledge and tease your wits in diverse areas of analytical and bioanalytical chemistry by viewing this collection.

In the present challenge, isotope dilution is the topic. And please note that there is a prize to be won (a Springer book of your choice up to a value of $€ 100)$. Please read on...

\section{Meet the isotope dilution challenge}

Isotope-dilution mass spectrometry (IDMS) is regarded as the most accurate quantitation strategy in chemistry $[1,2]$, and it relies upon mass-spectrometry analysis of a blend of sample (A) and isotopic internal standard (B). The isotopic standard is an isotopically enriched form of the analyte. Such materials are, in general, ideal internal standards because their behavior during sample preparation and instrumental analysis is nearly identical to that of the analyte, yet both substances can be distinguished by mass spectrometry because of their mass difference. If the analyte is monoisotopic (e.g., iodine) and the internal standard is constituted entirely of artificial

E. Pagliano $(\square)$

National Research Council of Canada, 1200 Montreal Road, Ottawa, ON K1A 0R6, Canada

e-mail: enea.pagliano@nrc-cnrc.gc.ca

E. Pagliano

e-mail: e.pagliano@libero.it isotopes not present in the sample (e.g., iodine-129), the amount of analyte $\left(n_{\mathrm{A}}\right)$ is given by:

$n_{\mathrm{A}}=n_{\mathrm{B}} \cdot R_{\mathrm{AB}}$

where $n_{\mathrm{B}}$ is the amount of internal standard and $R_{\mathrm{AB}}$ is the isotope amount ratio in the resulting blend $(\mathrm{AB})$ of analyte and isotopic standard. This formulation, however, overlooks the fact that natural materials almost always contain isotopes that make up the isotopic standard, and vice versa. This overlap can be accounted for by applying the following equation (see Table 1 for an explanation of all symbols):

$n_{\mathrm{A}}=n_{\mathrm{B}} \cdot \frac{R_{\mathrm{B}}-R_{\mathrm{AB}}}{R_{\mathrm{AB}}-R_{\mathrm{A}}} \cdot \frac{\sum R_{\mathrm{A}}}{\sum R_{\mathrm{B}}}$

In terms of a more commonly used mass fraction, the above equation can be rewritten as follows:

$w_{\mathrm{A}}=w_{\mathrm{B}} \cdot \frac{m_{\mathrm{B}(\mathrm{AB})}}{m_{\mathrm{A}(\mathrm{AB})}} \cdot \frac{R_{\mathrm{B}}-R_{\mathrm{AB}}}{R_{\mathrm{AB}}-R_{\mathrm{A}}} \cdot \frac{\sum R_{\mathrm{A}}}{\sum R_{\mathrm{B}}} \cdot \frac{M_{\mathrm{A}}}{M_{\mathrm{B}}}$

Eq. (3), known as single isotope dilution, represents an important development in analytical chemistry. This model bases the quantitation of the analyte in the sample on the isotopic internal standard, which is used as a primary calibrator $\left(w_{\mathrm{B}}\right)$. This is a limitation because the chemical purity of most isotopic standards is not known with adequate accuracy. This problem was resolved by the introduction of the double isotope dilution $[3,4]$, in which variable $w_{\mathrm{B}}$ of Eq. (3) is determined by reverse isotope dilution against a primary standard of natural isotopic composition $\left(\mathrm{A}^{*}\right)$. Mathematically,

$w_{\mathrm{A}}=w_{\mathrm{A} *} \cdot \frac{m_{\mathrm{A} *(\mathrm{~A} * \mathrm{~B})} \cdot m_{\mathrm{B}(\mathrm{AB})}}{m_{\mathrm{B}(\mathrm{A} * \mathrm{~B})} \cdot m_{\mathrm{A}(\mathrm{AB})}} \cdot \frac{\left(R_{\mathrm{A} * \mathrm{~B}}-R_{\mathrm{A}}\right) \cdot\left(R_{\mathrm{B}}-R_{\mathrm{AB}}\right)}{\left(R_{\mathrm{B}}-R_{\mathrm{A} * \mathrm{~B}}\right) \cdot\left(R_{\mathrm{AB}}-R_{\mathrm{A}}\right)}$

where $A * B$ is the blend of primary standard of natural isotopic composition and isotopic standard used for the reverse isotope 
Table 1 Symbols and quantities

Symbol Description

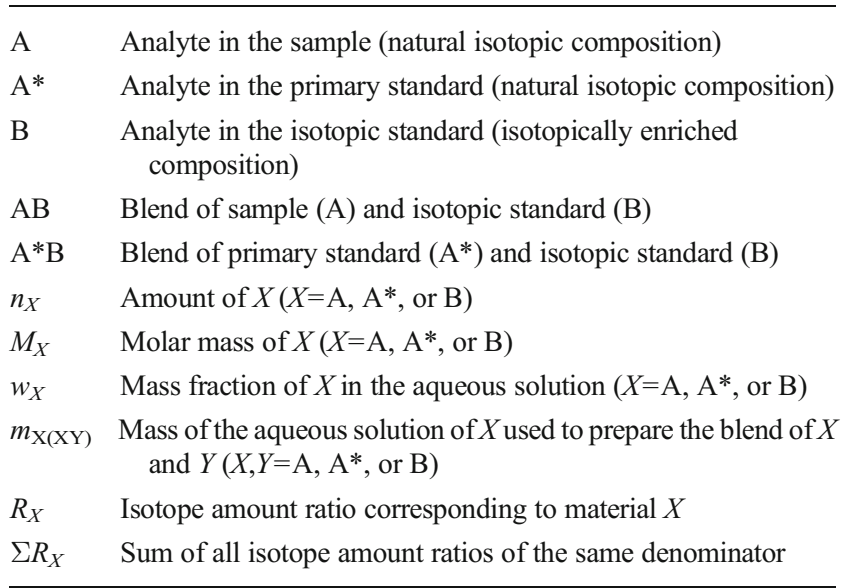

dilution. In this case the preparation and measurement of an additional blend $\mathrm{A} * \mathrm{~B}$ eliminates the need for $w_{\mathrm{B}}$. Eq. (4) relies on the assumption of the linearity of response of the detector in the range investigated, and of the identical isotopic composition of the analyte in A and in $\mathrm{A}^{*}$. Also, note that any biases in the measured isotope ratios cancel out as long as they are constant across all measurements.

Double isotope dilution relies on the isotopic composition of the natural $\left(R_{\mathrm{A}}\right)$ and enriched $\left(R_{\mathrm{B}}\right)$ material, and these two quantities can sometimes be difficult to establish in practice. The topic of this challenge is the illustration of an alternative isotope dilution design able to bypass direct knowledge of $R_{\mathrm{A}}$ and $R_{\mathrm{B}}$.

\section{The challenge}

The determination of bromide in groundwater was performed using a GCMS method $[5,6]$, and ${ }^{79} \mathrm{Br}$-enriched bromide was used as the isotopic standard. For this purpose the isotopic composition of the natural material $\left(R_{\mathrm{A}}\right)$ and of the isotopic standard $\left(R_{\mathrm{B}}\right)$ were measured experimentally. After this, one blend of sample and isotopic standard (AB) and three blends of primary standard and isotopic standard (A*B-1, A*B-2, A*B-3) were gravimetrically prepared and measured by GCMS. Experimental results are reported in Table 2.

The mass fraction of bromide in the groundwater sample can be determined by applying the double-isotope-dilution
Table 2 Experimental data

\begin{tabular}{llllll}
\hline Sample, $\mathrm{X}$ & $m_{\mathrm{A}} / \mathrm{g}$ & $w_{\mathrm{A}^{*}} /\left(\mathrm{ng} \mathrm{g}^{-1}\right)$ & $m_{\mathrm{A}^{*} / \mathrm{g}}$ & $m_{\mathrm{B}} / \mathrm{g}$ & $R_{\mathrm{X}} /(V / V)$ \\
\hline $\mathrm{A}\left(\right.$ and $\left.\mathrm{A}^{*}\right)$ & $\mathrm{n} / \mathrm{a}$ & $\mathrm{n} / \mathrm{a}$ & $\mathrm{n} / \mathrm{a}$ & $\mathrm{n} / \mathrm{a}$ & 1.018 \\
$\mathrm{~B}$ & $\mathrm{n} / \mathrm{a}$ & $\mathrm{n} / \mathrm{a}$ & $\mathrm{n} / \mathrm{a}$ & $\mathrm{n} / \mathrm{a}$ & 15.81 \\
$\mathrm{AB}$ & 2.00811 & $\mathrm{n} / \mathrm{a}$ & $\mathrm{n} / \mathrm{a}$ & 0.06002 & 4.226 \\
$\mathrm{~A} * \mathrm{~B}-1$ & $\mathrm{n} / \mathrm{a}$ & 97.44 & 1.02652 & 0.05992 & 6.143 \\
$\mathrm{~A} * \mathrm{~B}-2$ & $\mathrm{n} / \mathrm{a}$ & 97.44 & 2.00312 & 0.06013 & 4.215 \\
$\mathrm{~A} * \mathrm{~B}-3$ & $\mathrm{n} / \mathrm{a}$ & 97.44 & 4.10538 & 0.05989 & 2.764 \\
\hline
\end{tabular}

equation (Eq. (3)). However, the preparation of a second and a third blend, $\mathrm{A} * \mathrm{~B}-2$ and $\mathrm{A} * \mathrm{~B}-3$, enables the variables $R_{\mathrm{A}}$ and $R_{\mathrm{B}}$ to be ignored, in much the same fashion as double isotope dilution obviates the need for $w_{\mathrm{B}}$.

Can you calculate the mass fraction of bromide, analytically or graphically, using only the data from blends $A B, A^{*} B$ $1, A^{*} B-2$, and $A^{*} B-3$ ?

\section{References}

1. Meija J, Mester Z (2008) Anal Chim Acta 607:115-125

2. De Bièvre $P$ (1990) Fresenius J Anal Chem 337:766-771

3. Bloch K, Anker HS (1948) Science 107:228

4. Rosenblum C (1957) Anal Chem 29:1740-1744

5. D’Ulivo A, Pagliano E, Onor M, Pitzalis E, Zamboni R (2009) Anal Chem 81:6399-6406

6. Pagliano E, Mester Z, Meija J (2013) Anal Bioanal Chem 405:2879_ 2887

We invite our readers to participate in the Analytical Challenge by solving the puzzle above. Please send the correct solution to abc-challenge@springer.com by October 1, 2014. Make sure you enter "Isotope dilution challenge" in the subject line of your e-mail. The winner will be notified by e-mail and his/her name will be published on the "Analytical and Bioanalytical Chemistry" website at http://www.springer. $\mathrm{com} / \mathrm{abc}$ and in the journal (volume 407/issue 1), where the readers will find the solution and a short explanation.

The next Analytical Challenge will be published in 406/27, November 2014. If you have enjoyed solving this Analytical Challenge you are invited to try the previous puzzles on the $A B C$ homepage. 